\title{
Financial Payments to Teaching Hospitals by Companies Marketing Opioids
}

\author{
Timothy S. Anderson, MD, MAS ${ }^{\top}$ (D, Maxwell S. Krieger, BS ${ }^{2}$, Brandon D. L. Marshall, PhD², \\ Magdalena Cerdá, DrPH, MPH ${ }^{3,4}$, and Scott Hadland, MD, MPH, MS $5^{5,6,7}$
}

\begin{abstract}
'Division of General Medicine, Beth Israel Deaconess Medical Center, Brookline, MA, USA; ${ }^{2}$ Department of Epidemiology, Brown University School of Public Health, Providence, RI, USA; ${ }^{3}$ Department of Population Health, New York University School of Medicine, New York, USA; ${ }^{4}$ Center for Opioid Epidemiology and Policy, New York University School of Medicine, New York, USA; 5 Grayken Center for Addiction, Boston Medical Center, Boston, MA, USA; ${ }^{6}$ Department of Pediatrics, Boston Medical Center, Boston, MA, USA; ${ }^{7}$ Division of General Pediatrics, Department of Pediatrics, Boston University School of Medicine, Boston, MA, USA.
\end{abstract}

J Gen Intern Med 35(10):3108-10

DOI: $10.1007 / \mathrm{s} 11606-019-05596-1$

(C) Society of General Internal Medicine 2019

\begin{abstract}
A mid the national opioid overdose crisis, media reports and ongoing litigation have shed light on financial relationships between companies marketing opioid medications and teaching hospitals. Financial relationships between teaching hospitals and pharmaceutical companies may influence the education of trainees and physician prescribing practices, creating institutional conflicts of interest which can undermine public trust. ${ }^{1}$

While prior research indicates financial payments to physicians related to marketing of opioids are widespread and may contribute to increased prescribing frequency ${ }^{2}$ and dosing, ${ }^{3}$ little is known about opioid-related payments to academic teaching hospitals. Thus, we examined the prevalence and characteristics of publicly reported payments from companies marketing opioids to US teaching hospitals.
\end{abstract}

\section{METHODS}

We examined all non-research payments made by companies marketing opioids to teaching hospitals reported in the Centers for Medicare and Medicaid Services (CMS) Open Payments database. ${ }^{4}$ Data were available for payments occurring between August 1, 2013, and December 31, 2018. We identified companies marketing opioids as those reporting any payments related to opioids in the Open Payments database and those listed in the Food and Drug Administration National Drug Codes database as manufacture ring or distributing opioid products. ${ }^{5}$ We examined all opioids approved for pain management, excluding methadone and buprenorphine/naloxone which are also approved for the treatment of opioid use

Received October 8, 2019

Revised October 29, 2019

Accepted December 4, 2019

Published online December 17, 2019 disorder. Teaching hospitals were identified by CMS certification number. We calculated descriptive statistics on the number, dollar amount, and nature of payments related to opioid products and payments made by companies marketing opioids that were not linked to any product.

\section{RESULTS}

During the study period, 31 companies marketing opioids reported making payments to teaching hospitals, of which 18 companies reported making payments specifically linked to the marketing of opioid products (median value of opioidrelated payments per company $\$ 194,977$; interquartile range [IQR] $\$ 14,993$ to $\$ 561,250)$. Overall, there were 444 payments linked to opioid products totaling \$7,023,140 (median value of individual payment \$1348; IQR \$245 to \$20,291). Five opioids accounted for the majority of payments: oxymorphone, morphine, buprenorphine, oxycodone, and fentanyl (Table 1).

Fifty-eight teaching hospitals $(58 / 1282,4.5 \%)$ received opioid-related payments (median total value of payments received per teaching hospital \$1725; IQR \$675 to \$3500). The majority of payments to teaching hospitals were made for services rendered including consulting, participating in unaccredited education, and services other than consulting (Table 2).

In addition to payments linked to opioids, we identified 5168 payments made by 22 companies marketing opioids which were not linked to any opioid or non-opioid product; the total value of these payments was $\$ 120.0$ million.

\section{DISCUSSION}

Between 2013 and 2018, US teaching hospitals received over $\$ 7$ million in payments related to opioid products, primarily for providing consulting and speaking services. These findings add to prior studies of industry marketing of opioid products, which have focused exclusively on payments made to individual physicians. ${ }^{2,3}$ 
Table 1 Payments by Companies Marketing Opioids to Teaching Hospitals, August 2013-December 2018

\begin{tabular}{|c|c|c|c|c|c|}
\hline & Payment amount, \$ & No. payments & No. hospitals ${ }^{a}$ & No. companies & Product names \\
\hline All opioid products & $7,023,140$ & 444 & 58 & 18 & \\
\hline Oxymorphone & $1,883,204$ & 74 & 3 & 2 & $\begin{array}{l}\text { Opana } \\
\text { Oxymorphone }\end{array}$ \\
\hline Morphine sulfate & $1,843,534$ & 137 & 20 & 8 & $\begin{array}{l}\text { Embeda } \\
\text { Arymo } \\
\text { Morphine sulfate }\end{array}$ \\
\hline Buprenorphine ${ }^{\mathrm{b}}$ & $1,336,899$ & 88 & 24 & 7 & $\begin{array}{l}\text { Belbuca } \\
\text { Butrans } \\
\text { Buprenorphine }\end{array}$ \\
\hline Oxycodone & $1,243,320$ & 54 & 11 & 5 & $\begin{array}{l}\text { Oxecta } \\
\text { Oxycontin } \\
\text { Xartemis } \\
\text { Oxycodone }\end{array}$ \\
\hline Fentanyl & 589,688 & 48 & 18 & 3 & $\begin{array}{l}\text { Ionsys } \\
\text { Fentanyl }\end{array}$ \\
\hline Hydrocodone & 118,894 & 36 & 2 & 4 & $\begin{array}{l}\text { Zohydro } \\
\text { Hysingla }\end{array}$ \\
\hline Tapentadol & 4000 & 4 & 3 & 2 & Nucynta \\
\hline Hydromorphone & 1850 & 2 & 2 & 1 & Exalgo \\
\hline Tramadol & 1750 & 1 & 1 & 1 & Tramadol \\
\hline
\end{tabular}

${ }^{a}$ As defined by Open Payments reporting requirements, teaching hospitals include those receiving payment for Medicare direct graduate medical education, inpatient prospective payment system indirect medical education, or psychiatric hospital indirect medical education

${ }^{b}$ Buprenorphine medications exclude those formulated with naloxone which are FDA-approved for treatment of opioid use disorder

As a result of Open Payments database limitations which include reliance on company self-report ${ }^{6}$ and a high frequency of companies not reporting which product payments were linked to, our analyses may underestimate payments related to opioids made to teaching hospitals. As Open Payments provides limited information on reasons for payments beyond broadly defined categories, some payments may be related to improving education on safe prescribing or risk evaluation programs. To meet the stated goals of the Open Payments program, CMS should consider requiring manufacturers to provide contextual information on payments made to teaching hospitals, particularly those related to controlled substances.

Given the unique role teaching hospitals play in training clinicians to prescribe and critically evaluate new medical evidence, these institutions should consider voluntarily prohibiting payments related to marketing of opioids and restriction of other financial relationships related to opioids. ${ }^{1}$
Government entities and accreditation bodies should consider formal limits on the nature of financial relationships permissible between manufacturers of controlled medications and teaching hospitals.

Corresponding Author: Timothy S. Anderson, MD, MAS; Division of General Medicine Beth Israel Deaconess Medical Center, 1309 Beacon Street, Brookline, MA 02446, USA (e-mail: tsander1@bidmc. harvard.edu).

Author Contributions Dr. Anderson had full access to all the data in the study and takes responsibility for the integrity of the data and the accuracy of the data analysis.

Study concept and design: Anderson, Hadland

Acquisition, analysis, or interpretation of data: All authors

Drafting of the manuscript: Anderson

Critical revision of the manuscript for important intellectual content: All authors

Statistical analysis: Anderson, Krieger

Table 2 Payments from Companies Marketing Opioids to Teaching Hospitals, By Nature of Payment

\begin{tabular}{|c|c|c|c|c|}
\hline Nature of payment & Payment amount, \$ & No. payments & No. hospitals & No. companies \\
\hline Consulting fee & $3,777,644$ & 175 & 7 & 11 \\
\hline Compensation for services other than consulting ${ }^{\mathrm{a}}$ & $2,432,324$ & 99 & 1 & 7 \\
\hline Unaccredited and non-certified continuing education program ${ }^{\mathrm{b}}$ & 684,286 & 20 & 1 & 1 \\
\hline Space rental or facility fees & 96,905 & 83 & 40 & 6 \\
\hline Education & 17,724 & 18 & 18 & 2 \\
\hline Honoraria & 12,322 & 2 & 1 & 1 \\
\hline Travel and lodging & 1805 & 39 & 2 & 3 \\
\hline Food and beverage & 130 & 8 & 3 & 4 \\
\hline Non-research grant & 0 & 0 & 0 & 0 \\
\hline Royalty or license & 0 & 0 & 0 & 0 \\
\hline Charitable contribution & 0 & 0 & 0 & 0 \\
\hline Gift & 0 & 0 & 0 & 0 \\
\hline
\end{tabular}

${ }^{a}$ Full definition from Open Payments: Compensation for services other than consulting, including serving as faculty or as a speaker at an event other than a continuing education program

${ }^{b}$ Full definition from Open Payments: Compensation for serving as faculty or as a speaker for an unaccredited and non-certified continuing education program 
Obtained funding: Not applicable

Administrative, technical, or material support: Marshall, Hadland

Study supervision: Anderson, Hadland

Funding Information Dr. Hadland was supported by the National Institute on Drug Abuse (K23 DA045085) and the Thrasher Research Fund Early Career Award. Dr. Marshall and Mr. Krieger are supported by the National Institute of General Medical Sciences (P2OGM125507).

\section{Compliance with Ethical Standards:}

Conflict of Interest: Dr. Anderson reports serving as an uncompensated member of the Journal of General Internal Medicine editorial board. All other authors report no conflicts of interest.

Disclaimer: The views expressed herein are those of the authors and do not necessarily represent the views of their respective institutions.

Publisher's Note: Springer Nature remains neutral with regard to jurisdictional claims in published maps and institutional affiliations.
2009/Conflict-of-Interest-in-Medical-Research-Education-and-Practice. aspx.

2. Hadland SE, Cerdá M, Li Y, Krieger MS, Marshall BDL. Association of pharmaceutical industry marketing of opioid products to physicians with subsequent opioid prescribing. JAMA Intern Med. 2018;178(6):861-863.

3. Fleischman W, Agrawal S, Gross CP, Ross JS. Association of pharmaceutical manufacturer payments to physicians and prescribing dosage of opioids. J Gen Intern Med. 2019;34(7):1074-1076.

4. Centers for Medicare \& Medicaid Services. Open Payments. https://www. cms.gov/openpayments/explore-the-data/dataset-downloads.html. Published 2019. Accessed April 28, 2019.

5. Food and Drug Administration. National Drug Code Directory. https:// www.fda.gov/drugs/drug-approvals-and-databases/national-drug-codedirectory, Published 2019. Accessed April 28, 2019.

6. Anderson TS, Good CB, Gellad WF. Industry payments to academic physicians: a comparison of reporting to two government agencies. J Gen Intern Med. 2018;33(10):1604-1606.

Publisher's Note Springer Nature remains neutral with regard to jurisdictional claims in published maps and institutional affiliations.

\section{REFERENCES}

1. Institute of Medicine. Conflict of interest in medical research, education, and practice. National Academies Press; 2009. www.iom.edu/Reports/ 